\title{
Parent and child physical activity and sedentary time: Do active parents foster active children?
}

\author{
Russell Jago*, Kenneth R Fox, Angie S Page, Rowan Brockman and Janice L Thompson
}

\begin{abstract}
Background: Physical activity has many positive effects on children's health while TV viewing has been associated with adverse health outcomes. Many children do not meet physical activity recommendations and exceed TV viewing guidelines. Parents are likely to be an important influence on their children's behaviour. There is an absence of information about the associations between parents' and children's physical activity and TV viewing.

Methods: Year 6 children and their parent were recruited from 40 primary schools. Results are presented for the 340 parent-child dyads with accelerometer data that met $\mathrm{a} \geq 3$ day inclusion criteria and the 431 parent-child dyads with complete self-reported TV viewing. Over $80 \%$ of the dyads with valid TV viewing data included mothers and their child. Mean minutes of moderate to vigorous physical activity (MVPA), minutes of sedentary time per day and counts per minute were assessed by accelerometer. Self-reported hours of TV viewing were coded into 3 groups $(<2$ hours per day, 2-4 hours per day and $>4$ hours per day. Linear and multi-nominal regression models were run by child gender to examine parent-child associations.
\end{abstract}

Results: In linear regression models there was an association for the overall sedentary time of girls and their parents ( $t$ $=2.04 . p=.020$ ) but there was no association between girls' and parents' physical activity. There were no associations between parents' and boys' sedentary or physical activity time. For girls, the risk of watching more than 4 hours of TV per day, (reference $=2$ hours of TV per day), was 3.67 times higher if the girl's parent watched 2-4 hours of TV per day ( $p$ $=0.037$ ). For boys, the risk of watching more than 4 hours of TV per day, was 10.47 times higher if the boy's parent watched more than 4 hours of TV per day $(p=0.038)$.

Conclusions: There are associations in the sedentary time of parents and daughters. Higher parental TV viewing was associated with an increased risk of high levels of TV viewing for both boys and girls. There were no associations between the time that parents and children spend engaged in physical activity.

\section{Background}

Regular physical activity helps to prevent the development of heart disease [1], type 2 diabetes [2], obesity [3,4] and some cancers [5] and is also associated with improved mental well-being [6]. Among children and adolescents, physical activity has been associated with a lower body mass index [7] and lower mean values for cardiovascular risk factors [8-10]. Sedentary time, i.e. when people are not active has also been associated with increased adiposity among children [11]. Sedentary time does not, however, provide information about the activities in which a person is engaged and therefore there have

* Correspondence: russ.jago@bris.ac.uk

1 Department of Exercise, Nutrition \& Health Sciences, Centre for Sport, Exercise \& Health, University of Bristol, Tyndall Avenue, Bristol, BS8 1TP, UK

Full list of author information is available at the end of the article been recent calls to focus on sedentary activities as specific behaviours that are related to health outcomes [12]. The most studied sedentary behaviour is TV viewing and higher levels of TV viewing have been associated with higher body mass among youth $[7,13,14]$. Many children and adolescents do not meet physical activity guidelines and exceed TV viewing recommendations [15-18]. Children's physical activity levels decline steeply with age, particularly into adolescence [19-21] with the end of primary school (10-11 years of age) being a pivotal period of change $[20,22]$. Therefore, in order to prevent the development of cardiovascular and associated diseases there is a need to understand the factors that influence children's physical activity and TV viewing at this key transition age. 
Parents are likely to be an important influence on their children's physical activity and TV viewing behaviours [23-26]. In the UK there are now several types of family structure with many children not living with both of their biological parents. Therefore, for this paper, parent refers to the child's primary carer(s) which would usually be the child's biological parent but could also be a foster parent, grandparent or any other legal guardian. There may be several mechanisms underpinning parental impact such as parents and children sharing activities and thus engaging in activities together, parents setting examples and standards through role modelling, and providing home environments that either facilitate or prevent behaviours such as active play or TV viewing [23]. Understanding whether and/or how parent(s) influence children's physical activity and TV viewing could be important for identifying effective strategies for increasing children's physical activity.

A recent review of the associations between parent and child physical activity found that the current evidence is equivocal [23], with the majority of studies using self/ parental reports of physical activity, often in small samples [23]. It is not clear if parent-child physical activity associations are evident when more robust measures are utilised or when investigated in a UK context. Therefore, the aim of this study was to examine, using objective and reliable methods, associations between the physical activity, sedentary and TV viewing patterns of 10-11 year old children and their parents.

\section{Methods}

\section{Sampling and participants}

This study was part of a larger project, the Bristol 3Ps Project http://www.bristol.ac.uk/enhs/research/projects/ bristol3ps.html which examines the influences of peers and parents on physical activity participation in 10-11 year old children. Sampling was performed based on primary school location and the Index of Multiple Deprivation (IMD) score for school postcode. The IMD is an area level measure of deprivation produced by the UK government that includes income, health, educational and employment status [27] relative to a small geographical area around the participant's home address. IMD score therefore provides a global indicator of socioeconomic status (SES) that takes account of all the factors that are associated with SES. Higher IMD scores indicate higher levels of area deprivation i.e. lower SES. The IMDs of all state-funded schools within a 15-mile radius of the University of Bristol were obtained and divided into thirds to provide tertiles of school IMD. To provide a representative sample of local children we aimed to achieve an equal number of schools from each tertile. Fifty schools were approached and forty schools agreed to participate. The final sample approximately reflected IMD tertiles, with twelve schools from the high SES tertile group, 16 from the middle SES tertile and twelve from the low SES tertile. In total, 1684 Year 6 children and their parents were invited to take part in the study and 986 children and 539 parents provided data.

A briefing event was held at each school and all Year 6 pupils were invited to participate in a study examining parents and children's physical activity patterns. Information packs were sent home with all pupils and only those children who provided written informed parental consent took part. The self-identifying primary care provider, who will hereafter be referred to as the parent, was also invited to participate in the study and informed consent obtained. Children could participate without a parent taking part in the study. This study was approved by a University of Bristol ethics committee.

\section{Procedures}

Parental and child physical activity and sedentary time was assessed using Actigraph accelerometers (Actigraph, Florida) which have been shown to provide accurate and reliable indices of physical activity among both children and adults [28-30]. All children wore GT1M monitors which were set to record data every 10 seconds. This short epoch was used in order to capture the intermittent nature of children's physical activity [31]. Parents wore 7164 monitors set to record at 1 minute epochs. All participants were provided with instructions on how to wear the monitor and data were collected for five complete days, including two weekend days.

Although accelerometers provide information about sedentary time, they cannot provide contextual information about what the person is doing whilst sedentary. Therefore, to provide behavioural information, the accelerometer data was supported by parent and child selfreported measures of TV viewing. TV viewing was assessed using a single question which asked both parents and children to report the number of hours per day spent watching TV (none, $<1,1-2,2-3,3-4,4-5$ or $>5$ ). The assessment of TV viewing via a single question has been shown to correlate $(r=0.60)$ with 10 days of TV diaries among young children [32]. Moreover, a recent review reported that the single item approach has the highest validity of current methodologies [33].

Child height was measured using a SECA Leicester stadiometer (HAB International, Northampton) and weight using a SECA 899 digital scale (HAB International, Northampton). Child body mass index $\left(B M I=\mathrm{kg} / \mathrm{m}^{2}\right)$ was calculated and converted to an age and gender specific standard deviation score (BMI SDS) [34]. Parental height and weight were self-reported and parental BMI was calculated. Household postcode was obtained via parental report and the home associated IMD obtained for all participants. Since physical activity patterns have 
been shown to differ by the hours of daylight available [35], the hours of daylight on the first day of data collection were also calculated for each participant using standard UK tables [36] and treated as a confounder in all analyses.

\section{Data reduction}

Participants were included in the accelerometer analysis only if both the parent and child provided at least 3 days of valid accelerometer data. Based on the criteria used to analyse the accelerometer data in the US National Health and Nutrition Examination Survey (NHANES), periods in which 60 or more minutes of zero counts were obtained were interpreted as time when the monitor was not worn, and these periods were removed from the analysis [37]. Each day of accelerometer data was considered valid if data were obtained for at least 500 minutes. Mean counts per minute, which provides an indication of the overall volume of physical activity in which a person engages, was calculated for all participants. Mean minutes of moderate to vigorous intensity physical activity (MVPA), the intensity of activity that is recommended for optimal health [38] was also derived for both parents and children. For parents, physical activity that resulted in $\geq 2020$ CPM was treated as minutes of MVPA [39]. For children, a criteria of 3200 CPM was used, but as the GT1M monitors yield values that are 9\% different than the 7164 monitors [40], a correction factor of 0.91 was used to produce a cut-point of 2912 counts per minute or 485 counts per 10 second epoch. The accelerometer data were also used to derive minutes of sedentary time per day with thresholds of $<100$ CPM used for parents [41] and $<727(799 * 0.91)$ [29] for children. We recognise that the use of accelerometer cut-points is open to debate and that the selection of childhood thresholds in particular is hotly contested [42]. We opted for the 3200 and 799 childhood cut-points because these were obtained from laboratory calorimetery among U.S. children aged 6-16 years, the most robust validation method that has been employed [29]. Moreover, by also reporting mean counts per minute we provide an indicator of physical activity that is not affected by this issue.

The American Academy of Pediatrics (AAP) have recommended that children should spend less than 2 hours per day watching television [43]. As a result researchers have often used a criteria of $<2$ hours of TV viewing per day to describe children meeting the AAP guideline [44] or $>4$ hours to indicate children who greatly exceed this public health guideline $[45,46]$. The coding of the both the child and parent TV viewing data in this paper was modelled on these criteria with both child and parent TV viewing placed into 3 groups ( $<2$ hours per day, $2-4$ hours per day, and $>4$ hours per day). These three categories thereby provided an indication of the extent to which both the children and parents met ( $<2$ hours per day), exceeded (2-4 hours) or greatly exceeded ( $>4$ hours per day) the Academy of Pediatrics guidelines on television viewing for children [43].

\section{Analysis}

Descriptive statistics including means, percents and standard deviations were calculated for all variables. Scatterplots and Pearson correlations were used to examine the associations between parent and child accelerometer variables. As the graphs indicated a weak, linear association, linear regression models were then used to further investigate the associations between parent and child physical activity and TV viewing. As children's physical activity has been shown to differ by child gender $[15,47]$ all analyses were performed separately for boys and girls.

Models were built to examine if there was an association between parental BMI and the key exposure variables (parental behaviour). This was done by adding an interaction term between parental BMI and the parental exposure of interest into linear regression models that also included main effects for parental BMI and the exposure variable. Initial analyses indicated that none of these interaction terms were significant, therefore all models were run for all parent-child dyads with valid data, with parental BMI treated as a potential confounder. Linear regression models were then conducted to examine the extent to which parental physical activity (counts per minute) predicted child physical activity (counts per minute). The model was adjusted for child BMI SDS, parental BMI, household IMD score and hours of daylight on the first day of data collection. As the children were recruited from schools the model was also adjusted for the clustering of participants within schools, and robust standard errors were used. This process was then repeated separately for sedentary and MVPA minutes.

Multi-nominal logistic regression models with relative risk ratios (RR) were used to examine if either selfreported boys or girls' TV viewing was predicted by selfreported parental TV viewing patterns. Child TV viewing $(<2$ hours per day, $2-4$ hours per day, and $>4$ hours per day) was the outcome with $<2$ hours per day as the reference group. The main exposure variable was parental TV viewing ( $<2$ hours per day, 2-4 hours per day, and $>4$ hours per day) with the model also adjusted for child BMI SDS, household IMD score, hours of daylight on the first day of data collection and parental BMI. As per the linear models, robust standard errors were used to account for the clustering of participants in schools. Analysis was performed in STATA version 10.0 (College Station, Texas) and alpha was set at 0.05 . 


\section{Results}

Descriptive statistics for categorical variables are presented in Table 1. There were 431 parent-child dyads with some TV viewing questionnaire data and of these 352 $(81.7 \%)$ of the parents were mothers. There were 340 dyads with complete accelerometer data. The sample was equally split between boys and girls. Around half of the children (53.4\%) and parents (49.7\%) reported watching less than 2 hours of television per day.

Descriptive statistics for continuous variables are presented in Table 2. The children engaged in an average of 35.3 minutes of MVPA per day with a mean of 36.9 minutes per day for parents. Independent sample t-tests indicated that the mean BMI SDS score of the children with valid parent and child accelerometer data was significantly lower (.36 vs. .55) than those excluded from the analysis for insufficient data $(\mathrm{t}=2.34, \mathrm{p}=.020)$ but there was no difference in IMD score for those included or excluded in the analyses. Conversely t-tests indicated that the IMD of parent-child dyads with valid self-reported TV viewing data was lower (.41 vs. .54) indicating that more affluent households were more likely to provide data $(t=-3.06, p=.011)$ but there was no significant difference in child BMI SDS score.
Bivariate correlations between accelerometer derived child and parent physical activity behaviours are presented in Table 3. For girls, sedentary minutes was positively associated with parent sedentary minutes $(r=.190$, $\mathrm{p}=.012)$ and negatively associated with parent accelerometer counts per minute $(\mathrm{r}=-.150, \mathrm{p}=.049)$. For boys sedentary time was positively associated with parent sedentary time $(\mathrm{r}=.178, \mathrm{p}=.026)$.

Linear regression models used to predict accelerometer-derived physical activity variables are presented in Table 4. For girls, parental sedentary minutes predicted child sedentary minutes $(\mathrm{t}=2.43 . \mathrm{p}=.020)$ in a model that accounted for $12.1 \%$ of the variance. Parental CPM was not associated with girls' CPM and parental MVPA was not associated with girls MVPA. There were no statistically significant associations when the models were run for boys.

The multinomial logistic regression models are shown in Table 5. For girls, the risk of watching more than 4 hours of TV per day, (when compared to the reference group of watching less than 2 hours of TV per day), was 3.67 times higher if the girl's parent watched 2-4 hours of TV per day $(\mathrm{RR}=3.67,95 \% \mathrm{CI}=1.08$ to $12.42, \mathrm{p}=0.037)$. For boys, the risk of watching more than 4 hours of TV

Table 1: Descriptive statistics for categorical outcomes

$\mathbf{N}$

$\%$ of overall sample

\section{Child and parent TV viewing data}

Yes

No

Child and parent accelerometer data

Yes

No

\begin{tabular}{|c|c|c|}
\hline & $\mathbf{N}$ & $\%$ of included sample \\
\hline Girls (valid TV viewing dyad) & 215 & 49.9 \\
\hline Boys (valid TV viewing dyad) & 216 & 49.7 \\
\hline Mothers (valid TV viewing dyad) & 352 & 81.7 \\
\hline Father (valid TV viewing dyad) & 79 & 18.3 \\
\hline \multicolumn{3}{|l|}{ Child TV viewing per day } \\
\hline$<2$ hours per day & 230 & 53.4 \\
\hline 2-4 hours per day & 157 & 36.4 \\
\hline$>4$ hours per day & 44 & 10.2 \\
\hline \multicolumn{3}{|l|}{ Parent TV viewing per day } \\
\hline$<2$ hours per day & 214 & 49.7 \\
\hline 2-4 hours per day & 188 & 43.6 \\
\hline$>4$ hours per day & 29 & 6.7 \\
\hline
\end{tabular}


Table 2: Descriptive statistics for continuous variables

\begin{tabular}{|c|c|c|c|}
\hline & $\mathbf{N}$ & Mean & SD \\
\hline Child BMI $\left(\mathrm{kg} / \mathrm{m}^{2}\right)$ & 421 & 18.6 & 2.98 \\
\hline Child BMI SDS & 419 & .41 & 1.12 \\
\hline $\begin{array}{l}\text { Child accelerometer counts } \\
\text { per minute }\end{array}$ & 340 & 548.2 & 172.0 \\
\hline $\begin{array}{l}\text { Child sedentary minutes per } \\
\text { day }\end{array}$ & 340 & 552.3 & 103.1 \\
\hline Child MVPA minutes per day & 340 & 35.3 & 16.7 \\
\hline Parent BMI $\left(\mathrm{kg} / \mathrm{m}^{2}\right)$ & 381 & 25.25 & 5.33 \\
\hline $\begin{array}{l}\text { Parent accelerometer counts } \\
\text { per minute }\end{array}$ & 340 & 481.3 & 549.2 \\
\hline $\begin{array}{l}\text { Parent sedentary minutes per } \\
\text { day }\end{array}$ & 340 & 381.3 & 132.4 \\
\hline Parent MVPA minutes per day & 340 & 36.9 & 27.3 \\
\hline IMD Score & 418 & .15 & .12 \\
\hline Hours of daylight per day & 419 & 11.42 & 2.33 \\
\hline
\end{tabular}

per day, (when compared to the reference group of watching less than 2 hours of TV per day), was 10.47 times higher if the boy's parent watched more than 4 hours of TV per day $(\mathrm{RR}=10.47,95 \% \mathrm{CI}=1.13$ to 96.27 , $\mathrm{p}=0.038)$.

\section{Discussion}

In this dataset, the overall sedentary time of parents and daughters was associated but there was no association for parents and sons. In the adjusted regression models there was no association between either the intensity (MVPA) or volume (CPM) of physical activity in which parents and children engage. Thus, girls who have parents who spend a lot of time being sedentary are more likely to be sedentary but there were no associations between parent and child physical activity for either boys or girls. The disparity between parent and child sedentary time for boys and girls is not immediately clear. It could be the case that girls are more likely to sit and engage in seden- tary pursuits with their parents but we do not have data to explore this possibility. As such there is likely to be merit in further exploring why there is an association in sedentary time for girls and parents only and particularly if it is possible to work with parents to change girls' sedentary time. However, the absence of an association between parent and child physical activity suggests that strategies to promote parent and child physical activity together may not be fruitful at this age.

Higher parental TV viewing was associated with an increased risk that both boys and girls spent more than 4 hours per day watching TV. This finding is consistent with our previous research in which we have shown that children who live in a TV watching promoting household ( $\mathrm{TV}$ is on when the child comes home from school and meals are eaten in front of the TV) are more likely to exceed the AAP recommendation [44]. Collectively, these findings suggest that parent and child TV viewing are related and that developing strategies to change the home

Table 3: Correlations between parent and child accelerometer derived physical activity variables.

\begin{tabular}{|c|c|c|c|c|c|c|}
\hline & \multicolumn{3}{|c|}{ Girls ( $n=173$ ) } & \multicolumn{3}{|c|}{ Boys $(n=157)$} \\
\hline & $\begin{array}{l}\text { Child } \\
\text { Sedentary } \\
\text { minutes }\end{array}$ & $\begin{array}{l}\text { Child MVPA } \\
\text { minutes }\end{array}$ & Child CPM & $\begin{array}{l}\text { Child } \\
\text { Sedentary } \\
\text { Minutes }\end{array}$ & $\begin{array}{l}\text { Child MVPA } \\
\text { minutes }\end{array}$ & Child CPM \\
\hline Parent Sed & $.190 *$ & .055 & .041 & $.178^{*}$ & .041 & -.033 \\
\hline Parent MVPA & -.039 & .084 & .065 & -.002 & .044 & .106 \\
\hline Parent CPM & $-.150 *$ & .081 & .065 & -.102 & .002 & .133 \\
\hline
\end{tabular}

${ }^{*} \mathrm{p}<0.05$ 
Table 4: Linear regression models predicting child accelerometer counts per minute, minutes of sedentary time per day and minutes of MVPA per day by gender

\begin{tabular}{|c|c|c|c|c|c|c|c|c|}
\hline \multirow{2}{*}{$\begin{array}{l}\text { Exposure } \\
\text { Sedentary } \\
\text { minutes }\end{array}$} & \multicolumn{4}{|c|}{ Girls n = 139} & \multicolumn{4}{|c|}{ Boys $n=129$} \\
\hline & Coeff & $95 \% \mathrm{Cl}$ & $\mathbf{T}$ & $\mathbf{P}$ & Coeff & $95 \% \mathrm{Cl}$ & $\mathbf{T}$ & $\mathbf{P}$ \\
\hline & .204 & .03 to .370 & 2.43 & 0.020 & .097 & -.04 to 0.23 & 1.45 & 0.155 \\
\hline & \multicolumn{4}{|c|}{ Model R2 = 0.121} & \multicolumn{4}{|c|}{ Model R2 = 0.093} \\
\hline \multirow[t]{2}{*}{ CPM } & .117 & -.03 to 0.27 & 1.61 & 0.118 & .146 & -.07 to .37 & 1.35 & 0.185 \\
\hline & \multicolumn{4}{|c|}{ Model R2= 0.116} & \multicolumn{4}{|c|}{ Model R2 = 0.109} \\
\hline $\begin{array}{l}\text { MVPA } \\
\text { Minutes }\end{array}$ & .034 & -.10 to .17 & 0.53 & 0.598 & .049 & -.09 to .19 & 0.73 & 0.473 \\
\hline
\end{tabular}

TV environment may be important for reducing children's TV viewing.

This paper has significantly advanced current knowledge by providing a unique combination of both objective and self-reported data to document the associations between parent and child physical activity, sedentary time and TV viewing behaviours using robust measures and after adjustment for SES and demographic factors. However, the study has a number of limitations that need to be recognised. Firstly, parent and child dyad TV viewing data were only available for 431 children and the accelerometer data only met the inclusion criteria for 340 dyads. As noted above, children with valid accelerometer data had lower BMI values than those excluded while the children included in the TV viewing analyses tended to live in less deprived households than those who did not provide data. Caution is therefore required when interpreting the results, as it may be that associations are not comparable in less affluent households where, in the UK, there are higher levels of childhood and adult obesity and TV viewing [48-50]. Moreover, we have not been able to control for other potential confounders such as the geographical location of the home. Therefore, re-examining these issues in a dataset with a greater representation of participants from lower SES groups and a wider array of neighbourhood level variables is warranted.

It is important to recognise that parents were selected on the basis that they self-identified as the primary carer for their child and this yielded a sample that was over $80 \%$ female. Davison and colleagues [24] have previously reported that parental facilitation of 9 year old girls' physical activity differed by parental gender and therefore it may also be the case that direct modelling also differs by parental and child gender. In light of the small number of fathers who provided data it is not possible to examine if associations differed by parental gender or if associations were stronger in same sex dyads. The relative absence of paternal data may reflect contemporary care giver roles whereby mothers are generally more likely to complete surveys about their child than fathers. As such there is a need for more information from fathers in future datasets.

Although parent and child sedentary time were associated, the model accounted for only $12.1 \%$ of the variance. Similarly, the pseudo $\mathrm{R}^{2}$ for the multi-nominal regression models accounted for less than $8 \%$ of the variance in children's TV viewing. Moreover, although parental TV viewing was associated with an increase in the relative risk that children spent more than 4 hours per day watching $\mathrm{TV}$, the $95 \%$ confidence intervals for statistically significant findings $(\mathrm{RR}=3.67,95 \% \mathrm{CI}=1.08$ to 12.42 , and $\mathrm{RR}=10.47,95 \% \mathrm{CI}=1.13$ to 96.27 ) were very large indicating a lack of precision in associations. These findings therefore reinforce the need to further examine these associations in other datasets and search for potential 
Table 5: Multi-nominal logistic regression models in which child's' TV viewing is predicted by parental TV viewing categories ${ }^{1}$

\begin{tabular}{|c|c|c|c|c|}
\hline Girls $n=172$ & RR2 & $95 \% \mathrm{Cl}$ & $\mathbf{Z}$ & $\mathbf{P}$ \\
\hline \multicolumn{5}{|l|}{$\begin{array}{l}\text { Child 2-4 hours TV } \\
\text { per day }\end{array}$} \\
\hline $\begin{array}{l}\text { Parent 2-4 hours TV per } \\
\text { day }\end{array}$ & 1.39 & .85 to 2.26 & 1.32 & 0.186 \\
\hline $\begin{array}{l}\text { Parent } 4+\text { Hours of TV } \\
\text { per day }\end{array}$ & 1.49 & .43 to 5.12 & 0.63 & 0.528 \\
\hline \multicolumn{5}{|l|}{$\begin{array}{l}\text { Child 4+ hours TV per } \\
\text { day }\end{array}$} \\
\hline $\begin{array}{l}\text { Parent 2-4 hours TV per } \\
\text { day }\end{array}$ & 3.67 & 1.08 to 12.42 & 2.09 & 0.037 \\
\hline \multirow{2}{*}{$\begin{array}{l}\text { Parent } 4+\text { Hours of TV } \\
\text { per day }\end{array}$} & 3.05 & .34 to 27.85 & 0.99 & 0.322 \\
\hline & & & & Pseudo R2 = 0.041 \\
\hline Boys $n=174$ & $\mathbf{R R}$ & $95 \% \mathrm{Cl}$ & $\mathbf{Z}$ & $\mathbf{P}$ \\
\hline \multicolumn{5}{|l|}{$\begin{array}{l}\text { Child 2-4 hours TV } \\
\text { per day }\end{array}$} \\
\hline $\begin{array}{l}\text { Parent 2-4 hours TV per } \\
\text { day }\end{array}$ & 1.09 & .51 to 2.34 & 0.23 & 0.818 \\
\hline $\begin{array}{l}\text { Parent } 4+\text { Hours of TV } \\
\text { per day }\end{array}$ & 3.59 & 0.74 to 17.26 & 1.59 & 0.111 \\
\hline \multicolumn{5}{|l|}{$\begin{array}{l}\text { Child 4+ hours TV per } \\
\text { day }\end{array}$} \\
\hline $\begin{array}{l}\text { Parent 2-4 hours TV per } \\
\text { day }\end{array}$ & 0.72 & 0.26 to 2.07 & -0.59 & 0.552 \\
\hline \multirow{2}{*}{$\begin{array}{l}\text { Parent } 4+\text { Hours of TV } \\
\text { per day }\end{array}$} & 10.47 & 1.13 to 96.27 & 2.08 & 0.038 \\
\hline & & & & Pseudo R2 $=0.070$ \\
\hline
\end{tabular}

predictors of youth behaviour such as parental facilitation of activity and TV viewing.

It has frequently been suggested that parental modelling of activity behaviour is likely to be central in promoting physical activity among children [23-25]. Understanding the importance of parental modelling of physical activity has previously been difficult because studies have relied on less precise assessments of physical activity such as physical activity recall surveys [51]. The absence of an association between parent and child physical activity could be a function of the child's age, with 1011 years of age being a period when children's cognitive decision making abilities increase and they begin to assert a degree of independence from their parents
$[25,52,53]$. As such, it may be the case that there are associations among younger children. The absence of a direct association in physical activity is coherent with our qualitative work in which parents reported that they rarely engaged in physical activity with their child, spending more time arranging transport and supervision for their child's physical activity $[25,26]$. Collectively, these findings suggest that parental influence on the physical activity of British 10-11 year olds is likely to be facilitative in nature and not by modelling or copying of behaviours. Attention should therefore focus on understanding this association and identifying effective strategies for parents to use to enable their children to be as active as possible. 
The findings presented here raise a number of issues for both public health practice and research. Many adults, and particularly mothers, feel unable to engage in physical activity because they feel obligated to prioritise their time toward family caretaking responsibilities and may also have low levels of perceived physical activity competence and thus feel limited in how they can be physically active role models for their children [54-56]. Our data indicate that parents don't need to be active to influence their child's physical activity. Thus, we would suggest that a key public health message should be that all parents, regardless of their own activity level should be encouraged to promote physical activity and reduce sedentary time for their child.

The data presented here indicate that on the average, parents are engaging in similar amounts of MVPA as children but it seems that this is not activity in which parents are active with their children. In terms of future research this suggests that promoting strategies that focus on helping parents and children to be active on their own should be developed alongside those that promote parents and children being physically active together. Secondly, as our data indicate that parent-child co-participation in activity is unlikely to be a source of parental influence, any existing parental influence is likely to be a function of parental facilitation of physical activity. Therefore, there is a need to examine the nature of facilitative influence and particularly if parents can help their children to be active by encouraging active travel to school or promoting outdoor free-play in safe areas close to home [25].

\section{Conclusions}

The data presented in this paper demonstrate that there was an association between the sedentary time of girls and their mothers. Additionally, higher parental TV viewing was associated with higher child TV viewing among both boys and girls. There were no associations between the time that parents and children spend engaged in physical activity.

\section{Competing interests}

The authors declare that they have no competing interests.

\section{Authors' contributions}

The study was conceived by RJ, KRF, ASP and JLT. RJ performed all analysis and wrote the first draft of the paper. All authors provided key intellectual input into the paper and edited the paper.

\section{Acknowledgements}

This project was funded by a project grant from the British Heart Foundation (ref PG/06/142). This report is also research arising from a Career Development Fellowship (to Dr Jago) supported by the National Institute for Health Research. The views expressed in this publication are those of the authors and not necessarily those of the NHS, the National Institute for Health Research or the Department of Health.

\section{Author Details}

Department of Exercise, Nutrition \& Health Sciences, Centre for Sport, Exercise \& Health, University of Bristol, Tyndall Avenue, Bristol, BS8 1TP, UK

Received: 3 November 2009 Accepted: 15 April 2010 Published: 15 April 2010

\section{References}

1. Paffenberger RS, Hyde RT, Wing AL, Hsieh CG: Physical activity, all cause mortality, and longevity of college alumni. NEng/ J Med 1986, 314:605-613.

2. Kriska A: Can a physically active lifestyle prevent type 2 diabetes? Exerc Sport SciRev 2003, 31(3):132-137.

3. Kimm SY, Glynn NW, Obarzanek E, Kriska AM, Daniels SR, Barton BA, Liu K: Relation between the changes in physical activity and body-mass index during adolescence: a multi-centre longitudinal study. Lancet 2005, 366(9482):301-307.

4. Leskinen T, Sipila S, Alen M, Cheng S, Pietilainen KH, Usenius JP, Suominen $H$, Kovanen $V$, Kainulainen $H$, Kaprio J, et al:: Leisure-time physical activity and high-risk fat: a longitudinal population-based twin study. Int $\mathrm{J}$ Obes (Lond) 2009, 33:1211-1218.

5. Lee IM: Physical activity and cancer prevention--data from epidemiologic studies. Med Sci Sports Exerc 2003, 35(11):1823-1827.

6. Parfitt G, Eston RG: The relationship between children's habitual activity level and psychological well-being. Acta Paediatr 2005, 94(12):1791-1797.

7. Jago R, Baranowski T, Baranowski JC, Thompson D, Greaves KA: BMI from 3-6 $y$ of age is predicted by TV viewing and physical activity, not diet. Int J Obes Relat Metab Disord 2005, 29(6):557-564.

8. Jago R, Wedderkopp N, Kristensen PL, Moller NC, Andersen LB, Cooper AR, Froberg K: Six-year change in youth physical activity and effect on fasting insulin and HOMA-IR. Am J Prev Med 2008, 35(6):554-560.

9. Brage S, Wedderkopp N, Ekelund U, Franks PW, Wareham NJ, Andersen LB, Froberg K: Objectively measured physical activity correlates with indices of insulin resistance in Danish children. The European Youth Heart Study (EYHS). Int J Obes Relat Metab Disord 2004, 28(11):1503-1508.

10. Brage S, Wedderkopp N, Ekelund U, Franks PW, Wareham NJ, Anderson LB, Froberg K: Features of the metabolic syndrome are associated with objectively measured physical activity and fitness in Danish children: the European Youth Heart Study. Diabetes Care 2004, 27(9):2141-2148.

11. Steele RM, van Sluijs EM, Cassidy A, Griffin SJ, Ekelund U: Targeting sedentary time or moderate- and vigorous-intensity activity: independent relations with adiposity in a population-based sample of 10-y-old British children. Am J Clin Nutr 2009, 90(5):1185-1192.

12. Biddle SJ: Sedentary behavior. Am J Prev Med 2007, 33(6):502-504.

13. Viner RM, Cole TJ: Television viewing in early childhood predicts adult body mass index. J Pediatr 2005, 147(4):429-435.

14. Vandewater EA, Shim MS, Caplovitz AG: Linking obesity and activity level with children's television and video game use. J Adolesc 2004, 27(1):71-85.

15. Jago R, Anderson C, Baranowski T, Watson K: Adolescent patterns of physical activity: Differences by gender, day and time of day. Am J Prev Med 2005, 28(5):447-452.

16. Riddoch C, Andersen LB, Wedderkopp N, Harro M, Klasson-Heggebo L, Sardinha LB, Cooper AR, Ekelund U: Physical activity levels and patterns of 9- and 15-yr-old European children. Med Sci Sports Exerc 2004, 36(1):86-92.

17. Riddoch CJ, Mattocks C, Deere K, Saunders J, Kirkby J, Tilling K, Leary SD, Blair SN, Ness AR: Objective measurement of levels and patterns of physical activity. Arch Dis Child 2007, 92(11):963-969.

18. Deveriill C, Doyle M, Erens B, Falaschetti E, Hedges B, Malbut K, Primatesta P. Stamatakis E, Wardle H: The Health of Children and Young People. In Health Survey for England 2002 Edited by: Sprotson K, Primatesta P. London: Stationery Office; 2002

19. Kimm SY, Glynn NW, Kriska A, Barton BA, Kronsberg SS, Daniels SR, Crawford PB, Sabry ZI, Liu K: Decline in physical activity in black girls and white girls during adolescence. N Engl J Med 2002, 347(10):709-715.

20. Caspersen CJ, Pereira MA, Curran KM: Changes in physical activity patterns in the United States, by sex and cross-sectional age. Med Sci Sports Exerc 2000, 32(9):1601-1609. 
21. Goran MI, Gower BA, Nagy TR, Johnson RK: Developmental changes in energy expenditure and physical activity in children: evidence for a decline in physical activity in girls before puberty. Pediatrics 1998 101(5):887-891.

22. Nader PR, Bradley RH, Houts RM, McRitchie SL, O'Brien M: Moderate-tovigorous physical activity from ages 9 to 15 years. JAMA 2008, 300(3):295-305.

23. Gustafson SL, Rhodes RE: Parental correlates of physical activity in children and early adolescents. Sports Med 2006, 36(1):79-97.

24. Davison KK, Cutting TM, Birch LL: Parents' activity-related parenting practices predict girls' physical activity. Med Sci Sports Exerc 2003, 35(9):1589-1595.

25. Jago R, Thompson JL, Page AS, Brockman R, Cartwright K, Fox KR: Licence to be active: parental concerns and 10-11-year-old children's ability to be independently physically active. J Public Health (Oxf) 2009 in press.

26. Thompson JL, Jago R, Brockman R, Cartwright K, Page AS, Fox KR: Physically active families - de-bunking the myth? A qualitative study of family participation in physical activity. Child Care Health Dev 2009, 36(2):265-274.

27. Noble M, McLennan D, Wilkinson K, Whitworth A, Barnes H, Dibben C: The English Indices of Deprivation. London: Communities and Local Government; 2007:1-129.

28. Welk G, Schaben JA, Morrow JR: Reliability of accelerometry-based activity monitors: A generlizability study. Med Sci Sports Exerc 2004, 36(9):1637-1645.

29. Puyau MR, Adolph AL, Vohra FA, Butte NF: Validation and calibration of physical activity monitors in children. Obes Res 2002, 10(3):150-157.

30. Freedson PS, Melanson E, Sirad J: Calibration of the Computer Science and Application, Inc. Accelerometer. Medicine \& Science in Sports and Exercise 1998, 30(05):01-05.

31. Bailey RC, Olson J, Pepper SL, Porszasz J, Barstow TJ, Cooper DM: The level and tempo of children's physical activities: an observational study. Med Sci Sports Exerc 1995, 27(07):1033-1041.

32. Anderson DR, Field DE, Collins PA, Lorch EP, Nathan JG: Estimates of young children's time with television: a methodological comparison of parent reports with time-lapse video home observation. Child Dev 1985, 56(5):1345-1357.

33. Bryant MJ, Lucove JC, Evenson KR, Marshall S: Measurement of television viewing in children and adolescents: a systematic review. Obes Rev 2007, 8(3):197-209.

34. Cole TJ, Freeman JV, Preece MA: Body mass index reference curves for the UK, 1990. Arch Dis Child 1995, 73(1):25-29.

35. Page AS, Cooper AR, Griew P, Davis L, Hillsdon M: Independent mobility in relation to weekday and weekend physical activity in children aged 10-11 years: The PEACH Project. Int J Behav Nutr Phys Act 2009, 6:2.

36. Sunrise and sunset for UK (Bristol) [http://www.timeanddate.com/ worldclock/astronomy.html? $n=304]$

37. Troiano RP, Berrigan D, Dodd KW, Masse LC, Tilert T, McDowell M: Physical activity in the United States measured by accelerometer. Med Sci Sports Exerc 2008, 40(1):181-188.

38. Department of Health PA, Health Improvement and Prevention: At least five a week: Evidence of the impact of physical activity and its relationship to health: A report from the Chief Medical Officer. London: Department of Health, Physical Activity, Health Improvement and Prevention; 2004:i-vi.

39. Schmitz KH, Treuth M, Hannan P, McMurray R, Ring KB, Catellier D, Pate R: Predicting energy expenditure from accelerometry counts in adolescent girls. Med Sci Sports Exerc 2005, 37(1):155-161.

40. Corder K, Brage S, Ramachandran A, Snehalatha C, Wareham N, Ekelund U: Comparison of two Actigraph models for assessing free-living physical activity in Indian adolescents. J Sports Sci 2007, 25(14):1607-1611.

41. Healy GN, Dunstan DW, Salmon J, Cerin E, Shaw JE, Zimmet PZ, Owen N: Breaks in sedentary time: beneficial associations with metabolic risk. Diabetes Care 2008, 31(4):661-666.

42. Ekelund $\mathrm{U}$, Brage $\mathrm{S}$, Wareham NJ: Physical activity in young children. Lancet 2004, 363:1163.

43. American Academy of Pediatrics - Committee on Public Education: Children. Adolescents and Television. Pediatrics 2001, 107(2):423-426.

44. Jago R, Page A, Froberg K, Sardinha LB, Klasson-Heggebo L, Andersen LB: Screen-viewing and the home TV environment: The European Youth Heart Study. Prev Med 2008, 47:525-529.
45. Biddle SJ, Gorely T, Marshall SJ, Cameron N: The prevalence of sedentary behavior and physical activity in leisure time: A study of Scottish adolescents using ecological momentary assessment. Prev Med 2009, 48(2):151-155.

46. Marshall SJ, Gorely T, Biddle SJ: A descriptive epidemiology of screenbased media use in youth: a review and critique. J Adolesc 2006, 29(3):333-349.

47. Sisson SB, Church TS, Martin CK, Tudor-Locke C, Smith SR, Bouchard C, Earnest CP, Rankinen T, Newton RL Jr, Katzmarzyk PT: Profiles of sedentary behavior in children and adolescents: The US National Health and Nutrition Examination Survey, 2001-2006. Int J Pediatr Obes 2009:1-7.

48. Clarke P, O'Malley PM, Johnston LD, Schulenberg JE: Social disparities in BMI trajectories across adulthood by gender, race/ethnicity and lifetime socio-economic position: 1986-2004. Int J Epidemiol 2009, 38(2):499-509.

49. Ness AR, Leary S, Reilly J, Wells J, Tobias J, Clark E, Davey Smith G, Team AS: The social patterning of fat and lean mass in a contemporary cohort of children. International Journal of Pediatric Obesity 2006, 1:59-61.

50. Fairclough SJ, Boddy LM, Hackett AF, Stratton G: Associations between children's socioeconomic status, weight status, and sex, with screenbased sedentary behaviours and sport participation. Int J Pediatr Obes 2009, 4(4):299-305.

51. Vilhjalmsson R, Thorlindsson T: Factors related to physical activity: a study of adolescents. Soc Sci Med 1998, 47:665-675.

52. Smith PK, Cowie H, Blades M: Understanding children's development Fourth edition. Oford: Blackwell; 2003

53. Hillman M, Adams J, Whitelegg J: One false move.... a study of children's independent mobility London: Policy Studies Institute; 1990.

54. Eyler AA, Matson-Koffman D, Rohm Young D, Wilcox S, Wilbur J, Thompson JL, Sanderson BK, Evenson KR: Quantitative study of correlates of physical activity in women from diverse racial/ethnic groups: Women's Cardiovascular Health Network Project--introduction and methodology. Am J Prev Med 2003, 25(3 Suppl 1):5-14.

55. Eyler AA, Matson-Koffman D, Vest JR, Evenson KR, Sanderson B, Thompson JL, Wilbur J, Wilcos S, Rohm Young D: Environmental, policy, and cultural factors related to physical activity in a diverse sample of women: The Women's Cardiovascular Health Network Project - Summary and Discussion. Women and Health 2002, 36:123-134.

56. Tavares LS, Plotnikoff RC, Loucaides C: Social-cognitive theories for predicting physical activity behaviours of employed women with and without young children. Psychology, Health \& Medicine 2009, 14(2):129-142.

\section{Pre-publication history}

The pre-publication history for this paper can be accessed here: http://www.biomedcentral.com/1471-2458/10/194/prepub

\section{doi: 10.1186/1471-2458-10-194}

Cite this article as: Jago et al., Parent and child physical activity and sedentary time: Do active parents foster active children? BMC Public Health 2010, 10:194

\section{Submit your next manuscript to BioMed Centra and take full advantage of:}

- Convenient online submission

- Thorough peer review

- No space constraints or color figure charges

- Immediate publication on acceptance

- Inclusion in PubMed, CAS, Scopus and Google Scholar

- Research which is freely available for redistribution 